\title{
Wayfinding Sign pada Ruang Pameran Tetap di Museum Nasional Indonesia - Jakarta
}

\author{
Heru Budi Kusuma
}

Program Studi Desain Interior, Fakultas Seni Rupa dan desain, Universitas Tarumanagara - Jakarta

heruk@fsrd.untar.ac.id

Wayfinding atau orientasi topografi, merupakan kemampuan menentukan lokasi, menemukan tempat dalam fasilitas gedung. Sebagai media penunjuk arah, Wayfinding Sign yang diterapkan pada ruang pameran tetap belum memenuhi kebutuhan yang dapat memberikan informasi yang cukup, mengenai arah mana yang harus dituju untuk mencapai area tertentu, warna-warna yang tercantum dalam panel informasi pun tidak memberikan arti tertentu. Permasalahan pada Wayfinding Sign pada ruang pameran tetap yang dianalisis meliputi: Ukuran; dimensi tanda yang proporsional terhadap luas area dimana tanda tersebut berada,sehingga memungkinkan tanda tersebut dapat mudah terlihat. Warna; berkaitan dengan warna pada tanda telah sesuai peruntukannya dan memperhatikan warna disekitar tanda berada. Kontras; berkaitan dengan estetika tanda yang dominan terhadap kondisi disekitar tanda sehingga tanda tampak eksistensinya. Intensitas; berkaitan terhadap sesuatu yang dapat memberikan stimulus sehingga menarik perhatian terhadap tanda. Posisi ; berkaitan dengan perletakan tanda yang memperhatikan jangkauan penglihatan pengunjung yang mengarah ketempat tanda tersebut berada. Untuk memfokuskan penelitian dan menemukan hubungan antara satu data dengan data yang lain, maka penelitian ini menggunakan metode penelitian kualitatif. Data hasil observasi, pengukuran, deskripsi, dan analisis data dengan teknik Triangulasi Data diperoleh kesimpulan sebagai berikut: Directional Sign; menggunakan tanda 'warna' yang tidak ada hubungannya dengan lokasi lantai ruang pameran dan nuansa warna ruangan yang ditunjukan, dan terdapat sign yang menginformasikan arah yang tidak tepat. Informational Sign; tanda yang memberikan informasi tentang materi koleksi yang didisplay dalam ruang pameran tetap, sudah sesuai dan efektif. Identificational Sign; perletakannya yang tidak tepat sehingga menggangu kenyamanan pengunjung dalam membaca informasinya dan membuat posisi membaca yang tidak sehat dan aman.

Kata Kunci: Wayfinding, Directional Sign, Informational Sign, Identificational Sign

\section{Wayfinding Sign at Fixed Exhibition Room at National Museum of Indonesia - Jakarta}

Wayfinding or topographic orientation, is the ability to determine the location, find a place in a building facility. As a signpost, Wayfinding Sign that is applied to the exhibition space still does not meet the needs that can provide enough information, on which direction should be addressed to reach a certain area, the colors contained in the information panel did not give a certain meaning. Problems with Wayfinding Sign on fixed exhibition space analyzed include: Size; dimensional marks proportional to the area in which they are located, allowing them to be easily visible. Color; related to the color on the mark has been appropriate designation and pay attention to the color around the mark resides. Contrast; related to the aesthetics of the dominant sign to the condition around the sign so that the sign appears its existence. Intensity; relates to something that can provide a stimulus that draws attention to the mark. Position; relating to the marking placement that takes into account the visibility of the visitor leading to where the mark is located. To focus the research and find the relationship between one data with other data, then this research using qualitative research method. Data result of observation, measurement, description, and data analysis with Data Triangulation technique obtained conclusion as follows: Directional Sign; using a 'color' sign that has nothing to do with the floor location of the exhibit hall and the color tone of the room shown, and there is a sign that informs the improper direction. Informational Sign; a sign that provides information about the collection material displayed in a fixed exhibit space, is appropriate and effective. Identificational Sign; inappropriate placement so as to interfere with the comfort of visitors in reading the information and create an unhealthy and safe reading position.

Keywords : Wayfinding, Directional Sign, Informational Sign, Identificational Sign

Proses Review : 1 - 31 Maret 2018, Dinyatakan Lolos: 10 April 2018

doi: dx.doi.org/10.31091/mudra.v33i2.331 


\section{PENDAHULUAN}

Visi Museum Nasional; Terwujudnya Museum Nasional sebagai pusat informasi budaya dan pariwisata yang mampu mencerdaskan kehidupan bangsa, meningkatkan peradaban dan kebanggaan terhadap kebudayaan nasional, serta memperkokoh persatuan dan persahabatan antar bangsa. Salah satu Misinya; Meningkatkan penyajian informasi koleksi yang mampu mencerdaskan kehidupan bangsa serta menumbuhkan daya apresiatif, inovatif, dan imajinatif. Bapak Widodo selaku Kepala Bidang Konservasi dan Penyajian, menyatakan bahwa Story Line Pameran pihak museum ingin mempertahankan masa lalu. Penataan Pameran Tetap di Gedung "B" terdiri dari empat tema yaitu Pameran Tetap di lantai 1; Manusia dan Lingkungan, Ilmu Pengetahuan, Pameran Tetap di lantai 2; Teknologi dan Eknonomi, Pameran Tetap di lantai 3; Organisasi Sosial dan Pola Pemukiman dan, Pameran Tetap di lantai 4; Khasanah Emas dan Keramik. gun secara kompleks. Karena sebagai suatu kesatuan dari lingkungan, Wayfinding juga bersifat permanen dan diterapkan dalam lingkungan tersebut.

Wayfinding yang ada di ruang pameran tetap, akan diukur peran dan efektivitas dari tanda yang dimaksud berkaitan dengan tersampaikannya informasi yang dimaksudkan kepada pengunjung. Efektivitas merupakan tolok ukur keberhasilan dari tujuan akhir yang hendak dicapai. Wayfinding merupakan metode system tanda yang mengatur atau mengarahkan orang dalam aktivitasnya bersikulasi, agar mengikuti alurnya sesuai dengan yang diinginkan oleh sistem tanda. .Penelitian ini bertujuan untuk; a. Mengidentifikasi permasalahan Wayfinding yang ada dalam tata pameran tetap di Museum Nasional Indonesia-Jakarta, b. Mendeskripsikan kondisi Wayfinding yang digunakan dalam tata pameran tetap dan efektifitasnya, c. Mendeskripsikan manfaat penerapan Wayfinding yang dapat membantu pengunjung dalam membuat keputusan dan mengambil keputusan yang berkaitan dengan orientasinya selama berada didalam ruang pameran tetap.

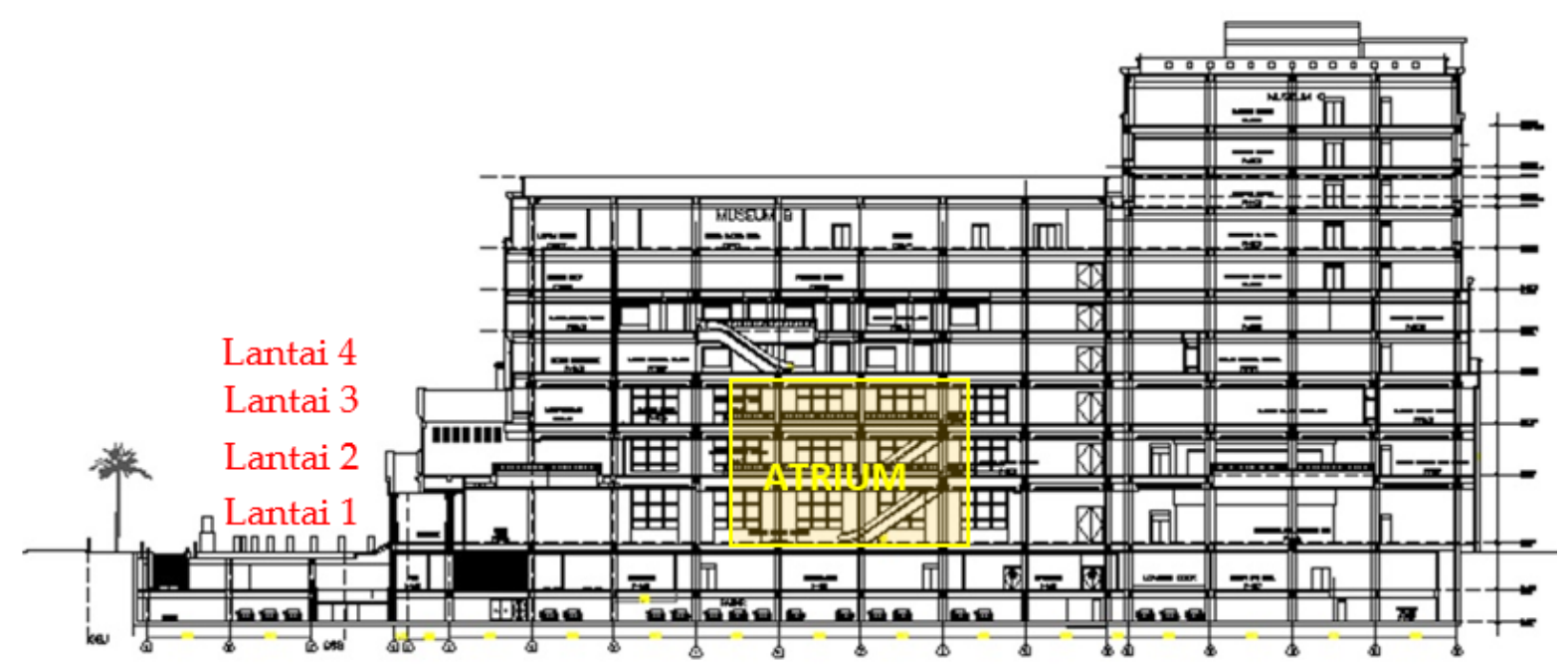

Gambar 1. Ruang Pameran Tetap di Gedung 'B' (Sumber: Museum Nasional)

Wayfinding atau orientasi topografi, merupakan kemampuan menentukan lokasi, menemukan tempat dalam fasilitas gedung. Selain peta, tanda-tanda arah, atrium sangat berperan dalam menetukan orientasi pengguna fasilitas ketika berada didalam gedung. Karena dengan atrium, pengunjung dapat menentukan orientasinya terhadap sirkulasi horisontal dan sirkulasi vertikal yang akan dipilihnya. Wayfinding selalu digunakan untuk beberapa keperluan seperti untuk mengidentifikasi suatu tempat atau sarana yang ada, mengarahkan khalayak ke tempat lain dan menginformasikan sesuatu kepada khalayak. Selain itu, penerapan Wayfinding dapat berupa sesuatu detail-detail yang sangat ditata terinci sehingga membentuk pola yang dapat mengarahkan alur sirkulasi dari suatu lingkungan. Wayfinding sangat penting sebagai suatu pemahaman manusia tentang suatu lingkungan yang semakin diban-

\section{METODE PENELITIAN}

Untuk memfokuskan penelitian dan menemukan hubungan antara satu data dengan data yang lain, dan untuk dapat melakukan analisis mendalam, maka penelitian ini menggunakan metode penelitian kualitatif. Dimana pengambilan data menggunakan tiga sumber data; pertama melakukan pengambilan data dengan teknik observasi terseleksi (mini tour observation), pada Wayfinding Sign diruang pameran tetap. Data kedua dari wawancara terstruktur (structured interview), yang dilakukan kepada para pengelola pameran tetap. Kemudian data ketiga dari angket tertutup hasil penelitian yang dilakukan pihak pengelola Museum Nasional - Jakarta terhadap Tingkat Kepuasan Pengunjung. Ketiga data tersebut dianalisis dengan metode triangulasi 


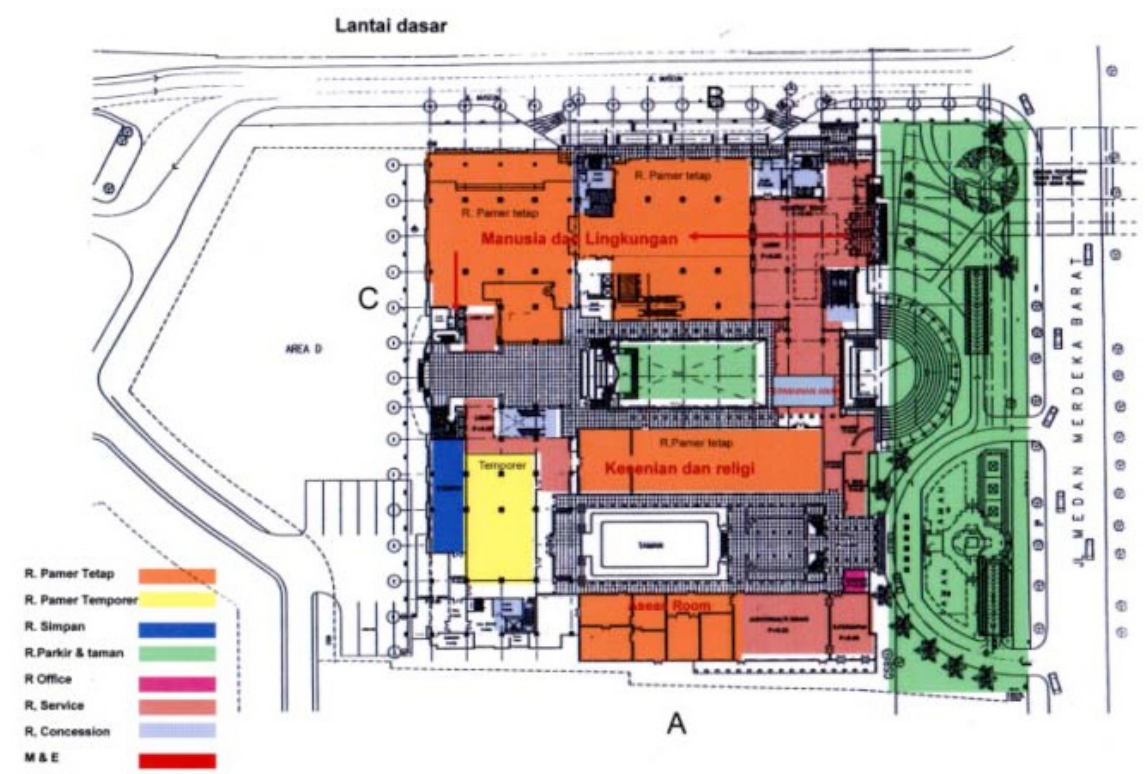

Gambar 2. Denah Lantai Dasar Museum Nasional - Jakarta (Sumber: Museum Nasional)

data, yang kemudian, dideskripsikan sehingga data tersebut dapat mudah dipahami.

Teknik observasi pada panel informasi meliputi pengambilan data berupa jarak keterbacaan, tinggi huruf, warna huruf, warna latar belakang, dan posisi ketinggian dari lantai, sebagaimana tersaji dalam instrumen pengambilan data yang ditunjukan pada tabel berikut:

Tabel 1. Form Pencatatan Hasil Pengukuran

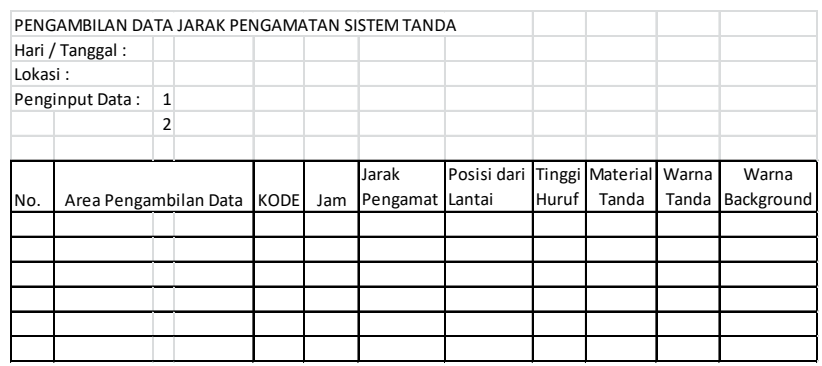

Teknik wawancara terstruktur dilakukan kepada narasumber, yaitu Ketua Bidang Penyajian dan Publikasi yaitu Bapak Drs. Widodo, Seksi Perancangan yang dikordinir oleh Ibu Nusi Lisabela, dan Seksi Penyajian yang dikordinir oleh Bapak Drs. Dian, serta Seksi Publikasi yang dikordinir oleh ibu Rini, S.S.

Analisis yang dilakukan merupakan metode Analisis Isi (Content Analysis), yaitu tekhnik analisis yang berhubungan dengan komunikasi atau isi komunikasi. Pada saat wawancara, peneliti sudah melakukan analisis terhadap jawaban yang diwawancarai. Bila jawaban yang diwawancarai setelah dianalisis terasa belum memuaskan, maka peneliti akan melanjutkan pertanyaan lagi, sampai tahap tertentu, diperoleh data yang dianggap kredibel. Miles and Huberman (1984), mengemukakan bahwa aktivitas dalam analisis data kualitatif dilakukan secara interaktif dan ber- langsung secara terus menerus sampai tuntas, sehingga datanya sudah jenuh. Aktivitas dalam analisis data, yaitu data reduction, data display, dan conclusions drawing/ verification reduction (Sugiyono, 2006:91).

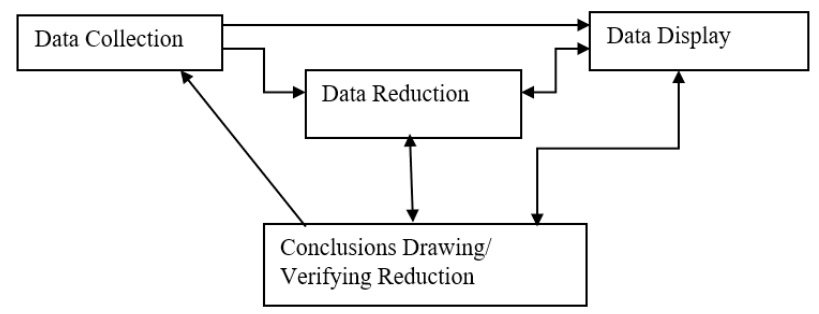

Diagram 1. Komponen Analisis Data (interactive model), (Sugiyono, 2006:92)

\section{ANALISIS DAN INTEPRETASI DATA}

\section{Orientational Sign}

Orientational Sign merupakan panel tanda yang berisi keterangan - keterangan yang jelas mengenai posisi keberadaan seseorang dalam suatu lingkungan, seperti peta, refrensi arsitektural dari sebuah gedung, dan denah sirkulasi jalur masuk dan keluar. Orientational Sign harus diletakkan didaerah yang umum, tempat dimana pengunjung harus membuat dan mengambil keputusan guna melanjutkan langkahnya menyusuri ruang-ruang pameran.

"The use of color :... Color can be used as pure function, to reflect or absorb light. . . . Color is a visual language. Color can alert or warn; they can be used to convey mood or to express emotion. . . . Color identifies. It provides instant discrimination between objects of similar or identical form and size. . . . Color can be used to modify the perception of space. . . . Color can be used to generate an emotional response. Colors can be selected to stimulate, 
or to calm. Color has physiological effects on the body. . . . Color is associative. . . . Color is symbolic. . . Color can be used to attract the eye, establishing emphasis or focus in compositon. . . Color suggests. It is impressional" (Linda Holtzschue, 2002: 3-4).

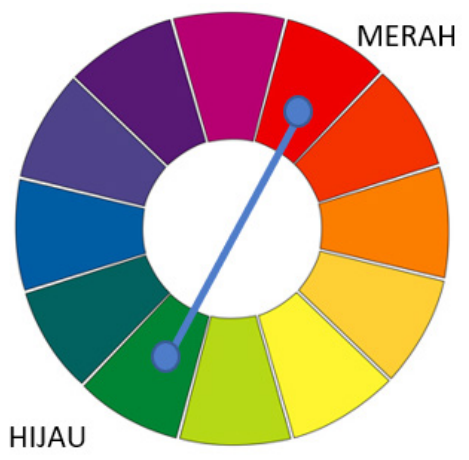

Gambar 3. Roda Warna

Sebagai salah satu elemen pembentuk sistem tanda, penggunaan warna merupakan 'Bahasa Visual' yang mengkomunikasikan maksud penggunaan warna pada tanda yang diwakilinya. Warna pada tanda bersifat asosiatif, karena penggunaan warna dapat sebagai tanda yang mengingatkan, tanda yang memperingatkan, tanda yang menganjurkan, tanda yang melarang, dan tanda yang memerintah. Sehingga penggunaan warna pada sistem tanda memiliki makna simbolis.

Bila mengkaji penerapan warna pada Gambar 2: Denah Lantai Dasar Museum Nasional, terlihat tidak diperhatikannya hubungan penggunaan warna dan tingkat territorial ruang yang diwakilinya. Mengamati gambar 'Roda Warna' diatas, tampak warna 'Merah' berseberangan dengan warna 'Hijau'. Bila warna 'Merah' sebagai tanda untuk ruang dengan teritorial 'Privat', dan warna 'Hijau' yang berseberangan dengan warna 'Merah' sebagai tanda untuk ruangan dengan teritorial 'Umum', maka penggunaan warna 'Jingga' kearah warna 'Kuning' menunjukkan tanda untuk ruangan dengan territorial 'Semi Privat', sedangkan penggunaan warna 'Biru' kearah warna 'Ungu' menunjukkan tanda untuk ruangan dengan territorial 'Semi Umum”. Sehingga dari uraian ini tampak adanya penggunaan warna yang tidak tepat pada penggunaan tanda:

Ruang Pameran Tetap dengan warna 'Jingga', sebaiknya menggunakan warna 'Ungu'

Ruang Pameran Temporer dengan warna 'Kuning', sebaiknya menggunakan warna 'Biru' dan

Ruang Simpan dengan warna 'Biru', sebaiknya menggunakan warna 'Jingga'.

Demikian pula tampak pada Gambar 4: Denah Museum Nasional, tidak tepatnya penggunaan warna 'Merah Muda' pada ruang Pameran Etnografi dan warna 'Jingga' pada Ruang Pameran Prasejarah. Pada ruang Pameran ini sebai-

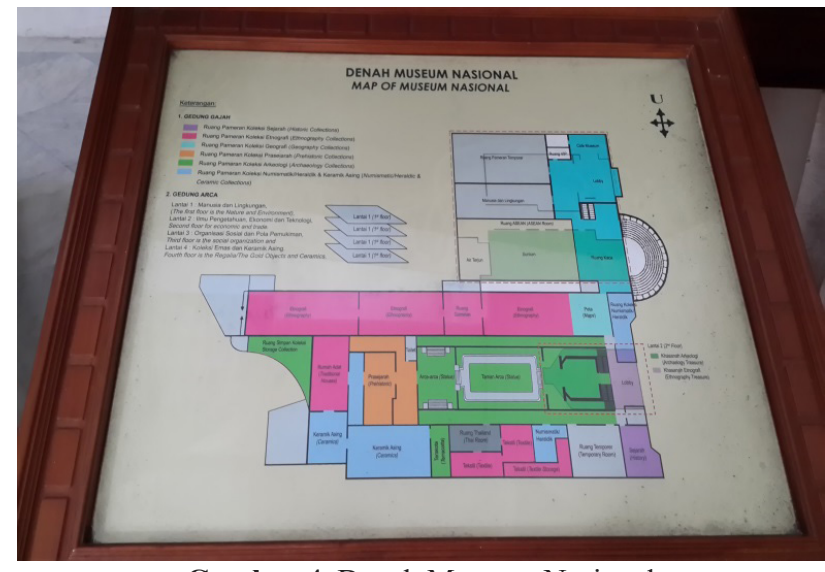

Gambar 4. Denah Museum Nasional

(Sumber: Museum Nasional)

knya menggunakan warna 'Biru' sampai warna 'Ungu'

\section{Informational Sign}

Semua tanda memberikan informasi namun Informational Sign lebih menunjuk pada spesifik dan detail tentang suatu informasi, dengan bentuk sign disesuaikan dengan informasi yang ingin disampaikan. Informational Sign umumnya diletakkan pada area pintu masuk dan tempat pengambil keputusan, yang bertujuan untuk memberikan informasi, mengurangi atau menghilangkan kebingungan dan mengurangi pertanyaan khalayak kepada petugas. Seperti tampak pada Gambar 5: Panel Informasi Ruang Pameran Tetap di Lantai 1 - 4, dimana menggunakan warna sebagai penanda lantai: warna 'Merah' untuk ruang pameran di lantai 4, warna 'Kuning' untuk ruang pameran di lantai 3, warna 'Biru' untuk ruang pameran di lantai 2, dan warna 'Hijau' untuk ruang pameran di lantai 1. Pengukuran tinggi huruf dan keterbacaan pada Informational Sign adalah sebagai berikut; jarak pengamatan: $575 \mathrm{~cm}$, posisi dari lantai: $147 \mathrm{~cm}$, dan tinggi huruf: $5,2 \mathrm{~cm}$ dan $1,8 \mathrm{~cm}$.

Ruang Pameran merupakan ruangan dengan teritorial 'Semi Umum', sebaiknya penggunaan warna sebagai penanda ruang pameran menggunakan variasi warna dari warna 'Biru' hingga warna 'Ungu'. Sehingga penggunaan warna 'Merah' dan 'Kuning' sebagai penanda ruangan 'Semi Umum' merupakan penggunaan warna yang tidak tepat.

\section{Directional Sign}

Directional Sign menunjukkan arah atau lokasi tujuan yang hendak dituju oleh pengunjung. Sign ini merupakan sebuah alat navigasi yang eksplisit sehingga diharapkan dapat membuat pengunjung menjadi lebih efisien dan nyaman dalam suatu lingkungan. Directional Sign ini sangat dibutuhan pada lingkungan yang kompleks dan luas. Sign ini bisa terdiri dari hanya satu sign, dimana hanya menunjukkan satu arah saja atau bisa terdiri dari banyak sign yang menunjukkan banyak arah dan tujuan seperti ditunjukan pada Gambar 6: Directional Sign di Lantai 1. Terdapat setidaknya 2 kekurangan pada Directional Sign, yang per- 


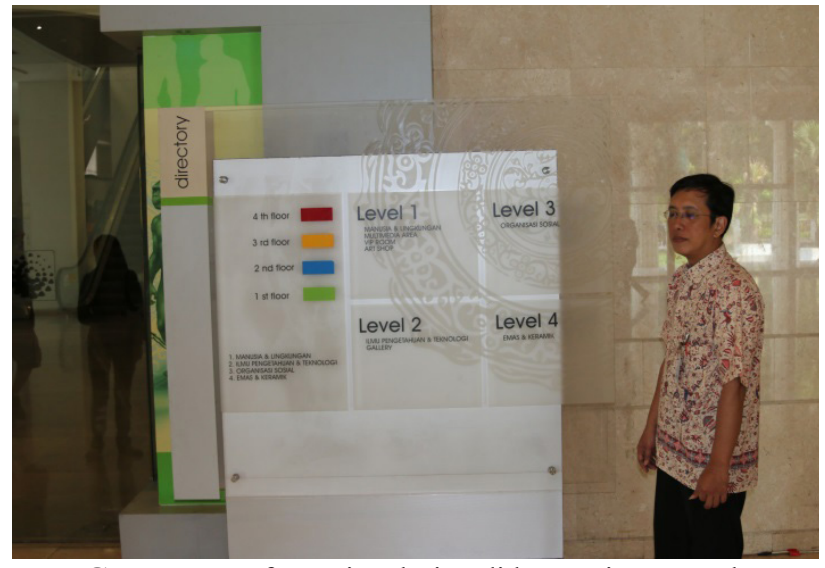

Gambar 5. Informational Sign didepan Pintu Masuk (Dokumen Pribadi)

tama adalah tidak dicantumkannya ruang pameran dilantai 4, dan yang kedua adalah tidak digunakannya tanda warna pada angka 2 yang disesuaikan dengan warna yang tercantum pada Panel Informasi (Informational Sign). Hasil pengukuran pada Directional Sign adalah sebagai berikut; jarak pengamatan: $768 \mathrm{~cm}$, posisi dari lantai: $140 \mathrm{~cm}$, tinggi huruf: $7,8 \mathrm{~cm}$ dan $3,5 \mathrm{~cm}$, dengan kketerbacaan hingga jarak $570 \mathrm{~cm}$.

\section{Identificational Sign}

Identificational Sign memberikan identitas suatu tempat atau sesuatu objek sesuai dengan jenis dan fungsinya. Biasanya berupa nama - nama tempat seperti toilet, sebutan untuk kamar kecil tempat seseorang membuang hajat; tempat informasi, sebutan untuk suatu tempat dimana pengunjung dapat bertanya mengenai segala informasi yang berhubungan dengan daerah tersebut. Sedangkan untuk nama - nama objek : selang pemadam api, sebutan untuk alat - alat yang digunakan untuk memadamkan kebakaran dan sebagainya. Sign ini juga berguna sebagai alat promosi jika diletakkan di pinggir jalan, contohnya papan nama sebuah toko atau kafe.

\section{Statutory (Regulatory) Sign}

Sign ini berupa peraturan - peraturan, larangan - larangan umum atau izin terhadap suatu aktivitas tertentu. Fungsi utamanya adalah untuk menjaga keselamatan seseorang dari suatu bahaya dan juga menginformasikan apa yang boleh dan tidak boleh dilakukan. Selain itu juga berguna dalam menginformasikan prosedur - prosedur akan suatu peristiwa darurat seperti kebakaran, gempa bumi dan sebagainya. Contoh dari sign ini adalah larangan untuk umum atau publik, khusus petugas, atau larangan yang mempunyai sifat emphasis tinggi seperti bahaya, radiasi, dilarang masuk, dilarang berenang dan sebagainya.

\section{Ornamental Sign}

Ornamental Sign berfungsi sebagai penghias atau elemen dekoratif yang betujuan untuk memperindah, meningkatkan atau mempercantik suatu penampilan secara keseluruhan dari suatu lingkungan atau sebagai suatu pelengkap

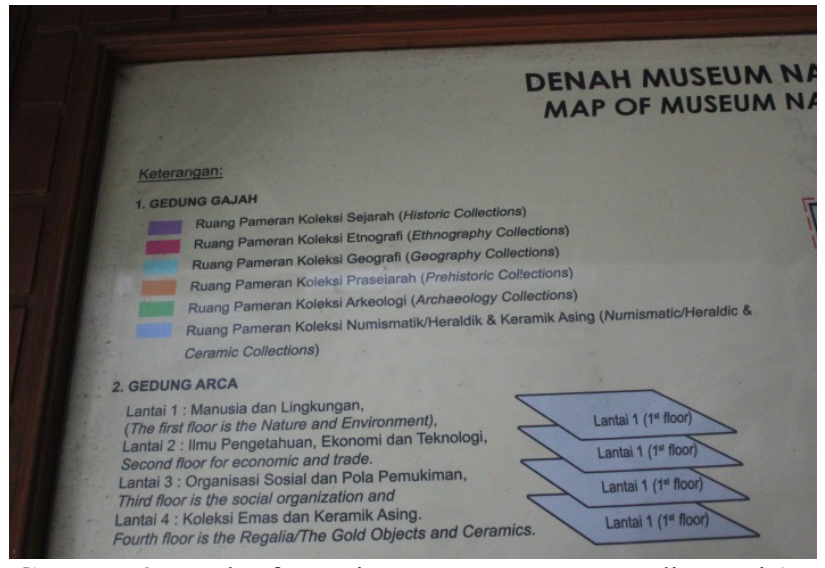

Gambar 6. Panel Informasi Ruang Pameran Tetap di Lantai 1 4 (Dokumen Pribadi)

elemen dari sebuah sign. Sign ini meliputi antara lain spanduk, banner, bendera, pagar, tugu peringatan dan bentuk - bentuk yang menarik perhatian.

\section{Hasil Pengukuran Sign System}

Untuk mengukur sign system yang didalamnya termasuk panel informasi dilakukan dari area Entrance (A) dimana orientasi pengunjung dimulai, selanjutnya diarea fasilitas sirkulasi vertikal (B) dimana pengunjung akan mengakses area pameran tetap yang berada di lantai 2, 3, dan 4. Area lobby lift dan escalator sebagai area orientasi pengunjung dilantai yang dituju (C) dan (D). Memasuki ruang pameran tetap, titik-titik pengukuran panel informasi dimulai saat memasuki ruang pameran tetap hingga keluar dari ruang pameran tetap, seperti ditunjukan oleh titik (E) sampai dengan titik (U) pada denah ruang pameran tetap lantai 2.

Sign system pada ruang publik dengan menggunakan tipe huruf Helvetica tinggi 78 milimeter menjadi dasar agar sign mudah terbaca hingga jarak 7 meter. Dari hasil pengukuran yang dilakukan terhadap obyek-obyek panel informasi dilokasi penelitian terlihat beragam jarak pengamatan, beragam posisi ketinggian, dan beragam ukuran tinggi huruf. Sedangkan warna huruf dan warna lingkungannya terlihat relatif sama, hal ini yang menyebabkan tingkat keterbacaan yang berbeda-beda untuk masing-masing obyek.

\section{SIMPULAN}

Dari data kualitatif hasil observasi, pengukuran, deskripsi, dan analisis data dengan teknik Triangulasi Data diperoleh kesimpulan sebagai berikut: Directional Sign; menggunakan tanda 'warna' yang tidak ada hubungannya dengan lokasi lantai ruang pameran dan nuansa warna ruangan yang ditunjukan, dan terdapat sign yang menginformasikan arah yang tidak tepat. Informational Sign; tanda yang memberikan informasi tentang materi koleksi yang didisplay dalam ruang pameran tetap, sudah sesuai dan efektif. Identificational Sign; perletakannya yang tidak tepat sehingga menggangu kenyamanan pengunjung dalam membaca informasinya dan membuat posisi mem- 


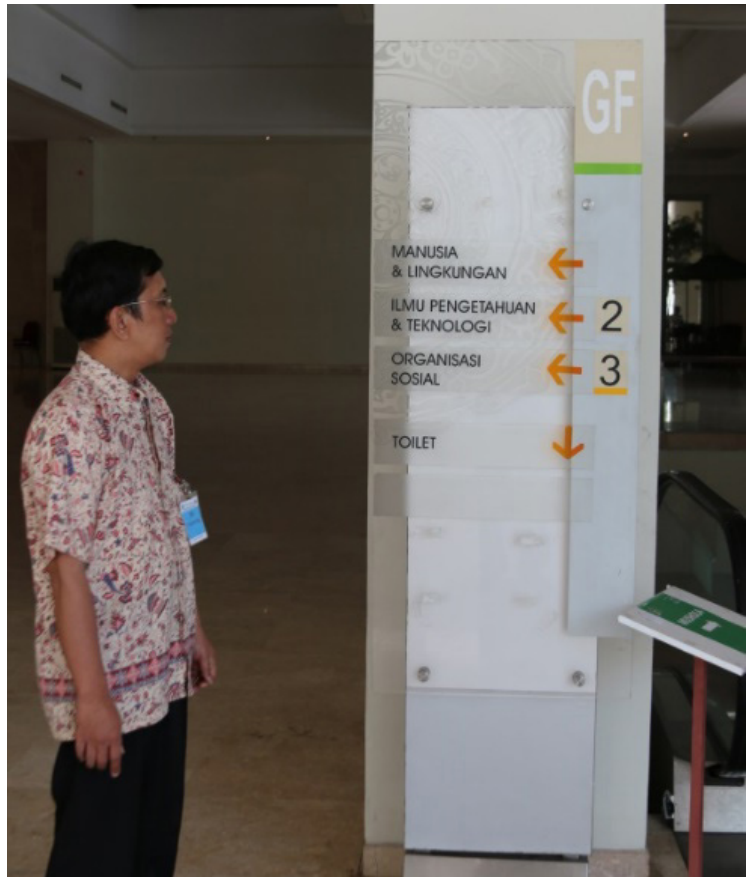

Gambar 7. Directional Sign di Lantai 1 (Dokumen Pribadi)

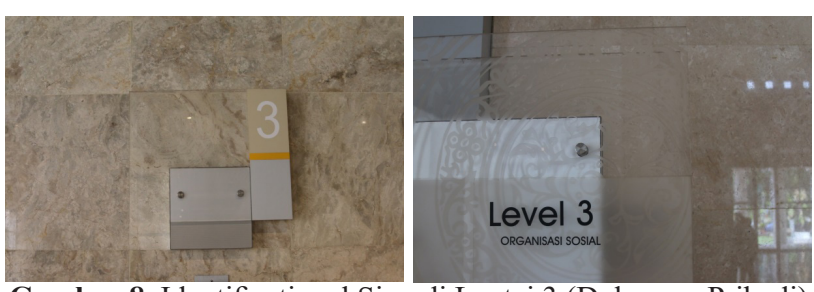

Gambar 8. Identificational Sign di Lantai 3 (Dokumen Pribadi)

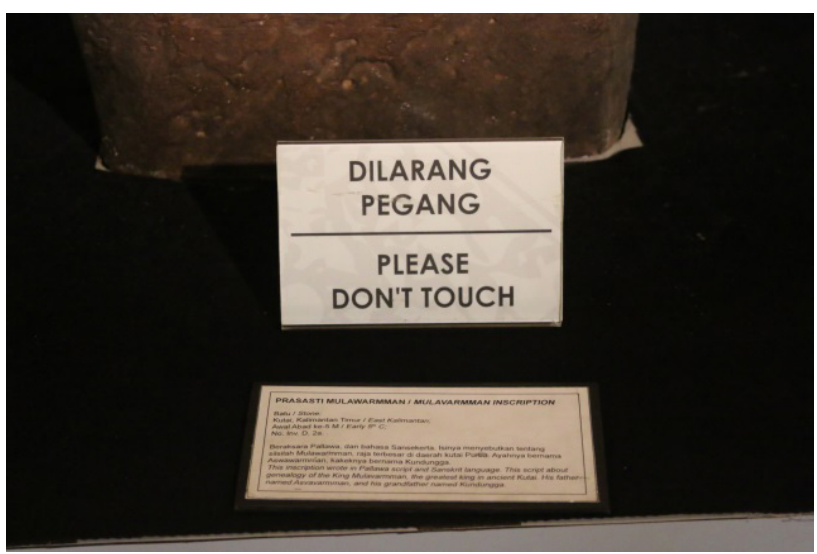

Gambar 9. Satutory Sign di Furniture Display (Dokumen Pribadi)

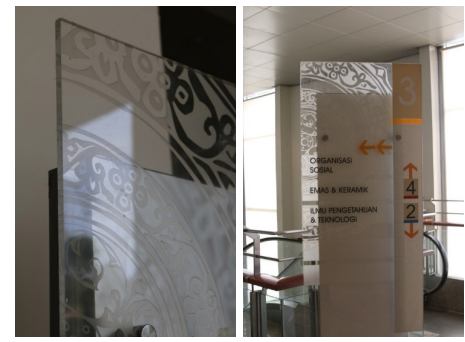

Gambar 10. Ornamental Sign pada Sign System (Dokumen Pribadi)

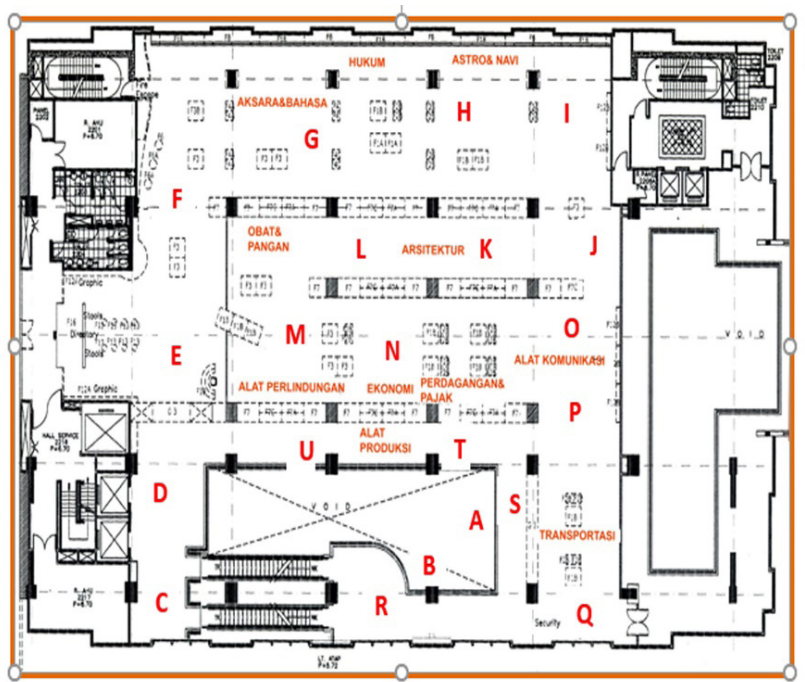

Gambar 11. Denah Pengambilan Data Penelitian Wayfinding (Dokumen Pribadi)

Tabel 2. Kartu pengambilan data pengukuran dilokasi penelitian (Dokumentasi Tim)

\begin{tabular}{|c|c|c|c|c|c|c|c|c|c|c|}
\hline No. & Area Pengambilan Data & KODE & Jam & \begin{tabular}{|l|} 
Jarak \\
Pngamat \\
\end{tabular} & $\begin{array}{l}\text { Posisi dr } \\
\text { Lantai }\end{array}$ & $\begin{array}{l}\text { Tinggi } \\
\text { Huruf }\end{array}$ & $\begin{array}{c}\text { Material } \\
\text { Tanda }\end{array}$ & $\begin{array}{l}\text { Warna } \\
\text { Tanda }\end{array}$ & \begin{tabular}{|c|} 
Warna \\
Panel
\end{tabular} & \begin{tabular}{|c|} 
Warna \\
Lingkungan
\end{tabular} \\
\hline \multirow[t]{3}{*}{1} & Panel di area Entrance & A & 10.14 & $575 \mathrm{~cm}$ & $147 \mathrm{~cm}$ & $5,2 \mathrm{~cm}$ & Sticker & Hitam & Bening & Abu-abu \\
\hline & & & & & & $1,8 \mathrm{~cm}$ & Sticker & Hitam & Bening & Kuning \\
\hline & & & & & & & & & & \\
\hline 2 & Panel di area Escalator & $B$ & 10.22 & $570 \mathrm{~cm}$ & $165 \mathrm{~cm}$ & $6,8 \mathrm{~cm}$ & Sticker & Hitam & Bening & Abu-abu \\
\hline & Lantai 1 & & & & & $2,6 \mathrm{~cm}$ & Sticker & Putih & Bening & Putih \\
\hline & & & & & & & & & & \\
\hline \multirow[t]{3}{*}{3} & Panel di area Escalator & c & 10.32 & $459 \mathrm{~cm}$ & $165 \mathrm{~cm}$ & $6,8 \mathrm{~cm}$ & Sticker & Hitam & Bening & Abu-abu \\
\hline & Lantai 2 & & & & & $2,6 \mathrm{~cm}$ & Sticker & Putih & Bening & Kuning \\
\hline & & & & & & & & & & \\
\hline \multirow[t]{3}{*}{4} & Panel di area Lift & $\mathrm{D}$ & 10.35 & $583 \mathrm{~cm}$ & $170 \mathrm{~cm}$ & $6,8 \mathrm{~cm}$ & Sticker & Putih & Bening & Kuning \\
\hline & Lantai 2 & & & & & & & & & \\
\hline & & & & & & & & & & \\
\hline \multirow[t]{3}{*}{5} & Panel di area Entrance & $\mathrm{E}$ & 10.44 & $768 \mathrm{~cm}$ & $240 \mathrm{~cm}$ & $7,8 \mathrm{~cm}$ & Cat & Putih & Kuning & Abu-abu \\
\hline & Ruang Pameran Lantai 2 & & & & & $3,5 \mathrm{~cm}$ & Sticker & Hitam & Bening & Abu-abu \\
\hline & & & & & & & & & & \\
\hline \multirow[t]{3}{*}{$E$} & Label Identitas & $\mathrm{F}$ & 10.46 & $347 \mathrm{~cm}$ & $60 \mathrm{~cm}$ & $1,1 \mathrm{~cm}$ & Tinta & Hitam & Putih & Abu-abu \\
\hline & Area display Prasasti & & & $71 \mathrm{~cm}$ & & $0,7 \mathrm{~cm}$ & Tinta & Hitam & Putih & Abu-abu \\
\hline & & & & & & & & & & \\
\hline \multirow[t]{3}{*}{7} & Label Identitas & G & 10.49 & $70 \mathrm{~cm}$ & $160 \mathrm{~cm}$ & $0,7 \mathrm{~cm}$ & Tinta & Hitam & Putih & Abu-abu \\
\hline & Area display Aksara & & & & & & & & & \\
\hline & & & & & & & & & & \\
\hline \multirow[t]{3}{*}{8} & Label Identitas & $\mathrm{H}$ & 10.53 & $65 \mathrm{~cm}$ & $120 \mathrm{~cm}$ & $0,7 \mathrm{~cm}$ & Tinta & Hitam & Putih & Abu-abu \\
\hline & Area display Hukum & & & & & & & & & \\
\hline & & & & & & & & & & \\
\hline \multirow[t]{3}{*}{9} & Label Identitas & 1 & 10.55 & $60 \mathrm{~cm}$ & $100 \mathrm{~cm}$ & $0,7 \mathrm{~cm}$ & Tinta & Hitam & Putih & Abu-abu \\
\hline & Area display Navigasi & & & & & & & & & \\
\hline & & & & & & & & & & \\
\hline \multirow[t]{3}{*}{10} & Label Identitas & J & - & - & - & - & - & - & - & - \\
\hline & Area Koridor & & & & & & & & & \\
\hline & & & & & & & & & & \\
\hline \multirow[t]{3}{*}{11} & Panel Informasi & $\mathrm{K}$ & 10.57 & $70 \mathrm{~cm}$ & $85 \mathrm{~cm}$ & $3,6 \mathrm{~cm}$ & Tinta & Hitam & Kuning & Kuning \\
\hline & Area display Arsitektur & & & & & $1,5 \mathrm{~cm}$ & & & & \\
\hline & & & & & & & & & & \\
\hline \multirow[t]{3}{*}{12} & Panel Informasi & $\mathrm{L}$ & 11.03 & \begin{tabular}{|l|}
$397 \mathrm{~cm}$ \\
\end{tabular} & $165 \mathrm{~cm}$ & $3,7 \mathrm{~cm}$ & Tinta & Hitam & Kuning & Kuning \\
\hline & Area Alat Obat-obatan & & & & & $1,2 \mathrm{~cm}$ & & & & \\
\hline & & & & & & & & & & \\
\hline \multirow[t]{3}{*}{13} & Panel Informasi & M & 11.08 & $310 \mathrm{~cm}$ & $180 \mathrm{~cm}$ & $3,6 \mathrm{~cm}$ & Tinta & Hitam & Kuning & Kuning \\
\hline & Area Alat Perlindungan & & & & & $1,2 \mathrm{~cm}$ & & & & \\
\hline & & & & & & & & & & \\
\hline \begin{tabular}{|l|}
14 \\
\end{tabular} & Panel Informasi & $\mathrm{N}$ & 11.11 & $400 \mathrm{~cm}$ & $120 \mathrm{~cm}$ & $3,7 \mathrm{~cm}$ & Tinta & Hitam & Kuning & Kuning \\
\hline & Area Alat Ekonomi & & & & & $1,2 \mathrm{~cm}$ & & & & \\
\hline 15 & Panellnformas: & 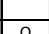 & 1114 & $80 \mathrm{~cm}$ & $130 \mathrm{~cm}$ & $07 \mathrm{~cm}$ & Tint? & Hitam & putih & Ahy-zhy \\
\hline & \begin{tabular}{|l} 
Area Alat Komunikasi \\
\end{tabular} & & & & & & & & & \\
\hline & & & & & & & & & & \\
\hline \begin{tabular}{|l|}
16 \\
\end{tabular} & Panel Informasi & $\mathrm{P}$ & 11.17 & $76 \mathrm{~cm}$ & $120 \mathrm{~cm}$ & $0,7 \mathrm{~cm}$ & Tinta & Hitam & Putih & Abu-abu \\
\hline & Area Koridor & & & & & & & & & \\
\hline & & & & & & & & & & \\
\hline \begin{tabular}{|l|}
17 \\
\end{tabular} & Panel Informasi & $Q$ & 11.19 & \begin{tabular}{|l|}
$627 \mathrm{~cm}$ \\
\end{tabular} & $100 \mathrm{~cm}$ & $2,6 \mathrm{~cm}$ & Sticker & Hitam & Bening & Kuning \\
\hline & Area Alat Transportasi & & & & & $2,5 \mathrm{~cm}$ & Sticker & Putih & Abu-aby & Kuning \\
\hline & & & & & & & & & & \\
\hline \begin{tabular}{|l|}
18 \\
\end{tabular} & Panel Informasi & $\mathrm{R}$ & - & - & - & - & - & - & - & - \\
\hline & & & & & & & & & & \\
\hline & & & & & & & & & & \\
\hline 19 & \begin{tabular}{|l} 
Panel Informasi \\
Area Void Transportasi
\end{tabular} & $\mathrm{s}$ & 11.22 & $\mathrm{~cm}$ & $120 \mathrm{~cm}$ & $0,7 \mathrm{~cm}$ & Tinta & Hitam & Putih & Abu-abu \\
\hline & & & & & & & & & & \\
\hline 20 & Panel Infor & $T$ & 11.24 & $280 \mathrm{~cm}$ & $100 \mathrm{~cm}$ & $3,7 \mathrm{~cm}$ & Tinta & Hitam & Putih & Kuning \\
\hline & \begin{tabular}{|l} 
Area Alat Produksi \\
\end{tabular} & & & & & $1,4 \mathrm{~cm}$ & Tinta & Hitam & Putih & Kuning \\
\hline & & & & & & & & & & \\
\hline \begin{tabular}{|l|}
21 \\
\end{tabular} & Panel Informasi & $\mathrm{u}$ & 11.27 & $270 \mathrm{~cm}$ & $100 \mathrm{~cm}$ & $2,6 \mathrm{~cm}$ & Tinta & Hitam & Putih & Kuning \\
\hline & Area Alat Produksi & & & & & $0,6 \mathrm{~cm}$ & Tinta & Hitam & Putih & Kuning \\
\hline & & & & & & & & & & \\
\hline
\end{tabular}


baca yang tidak sehat dan aman. Secara teknis Sign System dilingkungan Museum Nasional disarankan dapat memperhatikan beberapa hal berikut: Ukuran; berkaitan dengan dimensi tanda yang proporsional terhadap luas area dimana tanda tersebut berada,sehingga memungkinkan tanda tersebut dapat mudah terlihat. Warna; berkaitan dengan warna pada tanda telah sesuai peruntukannya dan memperhatikan warna disekitar tanda tersebut berada agar tampak kontras. Kontras; berkaitan dengan estetika tanda yang dominan terhadap kondisi disekitar tanda sehingga tanda tampak eksistensinya. Intensitas; berkaitan terhadap sesuatu yang dapat memberikan stimulus sehingga menarik perhatian terhadap tanda. Posisi; berkaitan dengan perletakan tanda yang memperhatikan jangkauan penglihatan pengunjung yang mengarah ketempat tanda tersebut berada.

Data kuantitatif dari hasil pengukuran yang dilakukan terhadap obyek-obyek panel informasi dilokasi penelitian terlihat beragam jarak pengamatan, beragam posisi ketinggian, dan beragam ukuran tinggi huruf. Sedangkan warna huruf dan warna lingkungannya terlihat relatif sama, hal ini yang menyebabkan tingkat keterbacaan yang berbeda-beda untuk masing-masing obyek.

Secara teknis Sign System dilingkungan Museum Nasional perlu dilakukan perbaikan dengan memperhatikan beberapa hal berikut :

Ukuran ; berkaitan dengan dimensi tanda yang proporsional terhadap luas area dimana tanda tersebut berada,sehingga memungkinkan tanda tersebut dapat mudah terlihat.

Warna ; berkaitan dengan warna pada tanda telah sesuai peruntukannya dan memperhatikan warna disekitar tanda tersebut berada agar tampak kontras.

Kontras ; berkaitan dengan estetika tanda yang dominan terhadap kondisi disekitar tanda sehingga tanda tampak eksistensinya.

Intensitas ; berkaitan terhadap sesuatu yang dapat memberikan stimulus sehingga menarik perhatian terhadap tanda.

Posisi ; berkaitan dengan perletakan tanda yang memperhatikan jangkauan penglihatan pengunjung yang mengarah ketempat tanda tersebut berada.

\section{DAFTAR RUJUKAN}

Arthur, Paul, Romedi Passini, Wayfinding : People, Signs and Architecture, Mc Graw-Hill Ryerson : New York, 1992

Asiarto, Lutfi, dkk., Pedoman Museum Indonesia, Direktorat Museum Dirjen Sejarah dan Purbakala Kementrian Kebudayaan dan Pariwisata, Jakarta, 2010

Broadbent, Geofrey, Richard Bent, Charles Jenks, Sign, Symbols, and Architecture, John Wiley and Sons : New York, 1980
Dean, David, Museum Exhibition, Theory and Practice, Routledge, New York, 1996

Djelantik, A.A.M, Estetika Sebuah Pengantar, Masyarakat Seni Pertunjukan Indonesia : Bandung, 2001

Edson, Gary, David Dean, The Handbook for Museum, Rotledge : New York, 1996

Follis, John \& Hammer, Dave Architectural Signing and Graphics. Broadway, NY : Whitney Library of Design, 1988

Ghautama, Gatot, Prioyulianto, Pedoman Museum Indonesia, Direktorat Museum Dirjen. Sejarah dan Purbakala Kementrian Kebudayaan dan Pariwisata, 2010

Sugiyono, Memahami Penelitian Kualitatif, Alfabeta : Bandung, 2005

Walker, Jhon A, Desain, Sejarah, Budaya, Sebuah Pengantar Komprehensif, Jalasutra : Yogyakarta, 2010 